\title{
Exploring the avian gut microbiota: current trends and future directions
}

\author{
David W. Waite and Michael W. Taylor* \\ Centre for Microbial Innovation, School of Biological Sciences, University of Auckland, Auckland, New Zealand
}

OPEN ACCESS

Edited by:

Nicole Webster,

Australian Institute of Marine Science,

Australia

Reviewed by:

Thomas Jefferson Sharpton,

Oregon State University, USA

David Berry,

University of Vienna, Austria

${ }^{*}$ Correspondence:

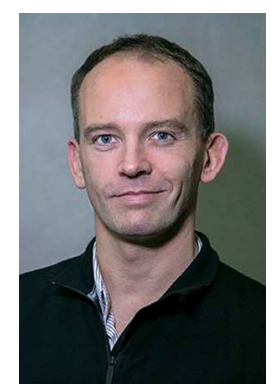

Michael W. Taylor

Ph.D. in Biological Sciences (2004),

University of New South Wales.

Postdoctoral research, Department of Microbial Ecology, University of Vienna

(2004-2006). Faculty position,

University of Auckland (2007-present).

Our team is interested in the ecology

of microorganisms associated with

animal (including human) hosts, which we study using a variety of molecular

and cultivation-based approaches. mw.taylor@auckland.ac.nz

Received: 19 April 2015 Accepted: 19 June 2015

Published: 03 July 2015

Citation:

Waite DW and Taylor MW (2015) Exploring the avian gut microbiota: current trends and future directions.

Front. Microbiol. 6:673.

doi: 10.3389/fmicb.2015.00673
Birds represent a diverse and evolutionarily successful lineage, occupying a wide range of niches throughout the world. Like all vertebrates, avians harbor diverse communities of microorganisms within their guts, which collectively fulfill crucial roles in providing the host with nutrition and protection from pathogens. Across the field of avian microbiology knowledge is extremely uneven, with several species accounting for an overwhelming majority of all microbiological investigations. These include agriculturally important birds, such as chickens and turkeys, as well as birds of evolutionary or conservation interest. In our previous study we attempted the first meta-analysis of the avian gut microbiota, using $16 \mathrm{~S}$ rRNA gene sequences obtained from a range of publicly available data sets. We have now extended our analysis to explore the microbiology of several key species in detail, to consider the avian microbiota within the context of what is known about other vertebrates, and to identify key areas of interest in avian microbiology for future study.

Keywords: bird, avian, microbiota, bacteria

\section{Introduction}

Birds represent a diverse and evolutionarily successful lineage, with over 10,000 extant species (Gill and Donsker, 2015) ranging from the diminutive bee hummingbird (weighing in at a mere $2 \mathrm{~g}$ ) to the towering ostrich ( $>100 \mathrm{~kg}$ and $>2 \mathrm{~m}$ tall). Such extreme morphological diversity is mirrored by the wide range of lifestyles adopted by avians, with the capacity of most species to fly facilitating the colonization of niches in ecosystems throughout the world. Bird diets vary widely, from fruit, seeds and foliage through to carrion and the capture of live animals. In this review article, we consider some of the challenges imposed on birds by their diet and lifestyle, and explore the potential relevance of gut microorganisms in assisting them to deal effectively with such constraints.

The gastrointestinal (GI) tracts of birds-like those of other vertebrate hosts-harbor a community of microbes, with densities as high as $10^{11} \mathrm{CFU} / \mathrm{g}$ in the hindgut (Barnes, 1972). While there is extensive evidence that microbial colonization of the GI tract brings benefits to host birds (Jin et al., 1998; Torok et al., 2008, 2011; Angelakis and Raoult, 2010; Zhang et al., 2011; Cao et al., 2012; Stanley et al., 2012), there are also pathways through which the normal colonization of microbes can be of detriment (Ford and Coates, 1971; Potti et al., 2002; Cao et al., 2012; Singh et al., 2013). Our knowledge of the avian microbiota has arguably lagged behind that of many other vertebrates, most notably humans (Turnbaugh et al., 2007) and mice (Benson et al., 2010; McKnite et al., 2011; Campbell et al., 2012; Hildebrand et al., 2013) but also other mammals, insects, and even fish (Sullam et al., 2012; Engel and Moran, 2013). In recent years, however, the data generated in avian microbiology have markedly increased (Supplemental Table S1, Supplemental Figure S1). It is now evident that the gut microbiota influences the health and physiology of vertebrate hosts, with recognized roles for the vertebrate microbiota in nutrition, gut development and regulation of host physiology. 
Technological advances, most notably the advent of next-generation sequencing platforms, such as 454 GS FLX pyrosequencing and the Illumina HiSeq/MiSeq, have reduced the costs of sequencing by orders of magnitude, enabling unprecedented insights into both the diversity and function of microbes within the vertebrate GI tract. Large-scale sequencing of $16 \mathrm{~S}$ rRNA genes from GI bacteria and archaea has been particularly profitable, with recent efforts to infer functional characteristics from 16S rRNA data also showing real promise (Zaneveld et al., 2010; Muegge et al., 2011; Langille et al., 2013). Our recent article (Waite and Taylor, 2014) represented the first attempt to unify the current data pertaining to avian microbiology into a single meta-analysis and to reveal the influence of environment and lifestyle on the avian microbiota.

The revolution in $16 \mathrm{~S}$ rRNA gene sequencing has seen earlier studies of microbial physiology within birds complemented by investigations into the diversity and phylogeny of avian gut microbes. Research foci have recently included the variation in microbial community structure along the GI tract, the effect of diet and age, and for some hosts the influence of factors such as captivity, antibiotic treatment, or pathogen colonization (Table 1) (Waite and Taylor, 2014). While commercially

TABLE 1 | Summary of studies investigating the impact of biological and non-biological factors on the avian microbiota.

\begin{tabular}{|c|c|c|}
\hline Factor & Host & Study \\
\hline \multirow{5}{*}{$\begin{array}{l}\text { Variation along the Gl } \\
\text { tract }\end{array}$} & Chicken & Bjerrum et al., 2006 \\
\hline & & Gong et al., 2007 \\
\hline & Turkey & Torok et al., 2008 \\
\hline & Hoatzin & Godoy-Vitorino et al., 2012 \\
\hline & Kakapo & Waite et al., 2012 \\
\hline \multirow[t]{5}{*}{ Host age } & Chicken & Van Der Wielen et al., 2002 \\
\hline & & Lu et al., 2003 \\
\hline & & Scupham, 2007 \\
\hline & Hoatzin & Godoy-Vitorino et al., 2010 \\
\hline & Kittiwake & Van Dongen et al., 2013 \\
\hline \multirow{8}{*}{$\begin{array}{l}\text { Dietary and probiotic } \\
\text { manipulation }\end{array}$} & Chicken & Jin et al., 1998 \\
\hline & & Rubio et al., 1998 \\
\hline & & Blanco et al., 2006 \\
\hline & & Janczyk et al., 2009 \\
\hline & & Hammons et al., 2010 \\
\hline & & Torok et al., 2011 \\
\hline & & Stanley et al., 2012 \\
\hline & & Dewar et al., 2014b \\
\hline \multirow{5}{*}{$\begin{array}{l}\text { Captivity and antibiotic } \\
\text { treatment }\end{array}$} & Capercaillie & Wienemann et al., 2011 \\
\hline & Kakapo & Waite et al., 2014 \\
\hline & Turkey & Scupham et al., 2008 \\
\hline & Parrots & Xenoulis et al., 2010 \\
\hline & Penguin & Singh et al., 2013 \\
\hline
\end{tabular}

Note that many of these studies investigate multiple facets of the microbiota so may overlap with other categories. important bird species such as broiler chickens and turkeys have long received attention from microbiologists, other host avians such as the folivorous hoatzin, carnivorous penguins, scavenging vultures, and critically endangered kakapo have also come under recent scrutiny (Figure 1). Here we re-examine existing knowledge of the avian microbiota, particularly within the context of the wider vertebrate microbiota, and identify the key outstanding questions in avian microbiology.

\section{Different Lifestyles, Different Challenges}

The plethora of ecological strategies that have been adopted by avians means that, collectively, birds have to cope with a wide range of gastronomic challenges. This is reflected in the large variation in organ morphology among different bird species, although despite these often substantial differences the only avian lineage showing major differences from the "standard" gut layout is that of the psittacines (parrots), which lack ceca (Stevens and Hume, 1998). The ceca are a pair of finger-like appendages protruding from the junction of the small and large intestine which facilitate nitrogen cycling, carbohydrate fermentation and aid water retention (McNab, 1973; Mead, 1989; Józefiak et al., 2004). The nutritional characteristics of different bird diets vary greatly, while toxins of both plant and carrion origin may also be encountered by certain species. While inter-individual variation exists within the avian microbiome, this effect is overshadowed by factors such as diet or host age. As shown for other vertebrates (Ley et al., 2008), one would expect the GI microbiota of avians

\section{KEY CONCEPT 1 | Microbiota vs. microbiome \\ Although sometimes used synonymously, these terms are generally meant to describe subtly different things. Microbiota refers to the community of microorganisms within a given environment (e.g., the avian gut), while microbiome describes the collective genomes of all these microbial species.}

to reflect their particular lifestyle. Here, we consider some of the better-studied avian hosts and their diets and seek to illustrate the enabling role played by gut microbes within these diverse species.

The hoatzin (Opisthocomus hoazin; Figure 1) of South America is something of a biological anomaly. Unlike most birds, it feeds mostly on leaves and-uniquely among avians-carries out foregut fermentation in an enlarged crop (Grajal et al., 1989), making its digestive strategy more like that of a ruminant than a bird. Indeed, the hoatzin foregut microbiota-dominated by members of the Bacteroidetes, Firmicutes, and Proteobacteria-is more similar to that of a cow's rumen than it is to its' own hindgut microbiota, demonstrating the importance of organ function in determining microbial community composition (GodoyVitorino et al., 2012). The hoatzin crop and cow rumen thus represent an excellent example of evolutionary convergence: a diet dominated by plant fibers requires a fermentation chamber of sufficient volume to retain this refractory material until its microbial breakdown into host-assimilable products such as short-chain fatty acids. Mechanical considerations predict that such an enlarged crop would preclude flying, and yet the hoatzin is capable of flight. This may be due to the highly selective 

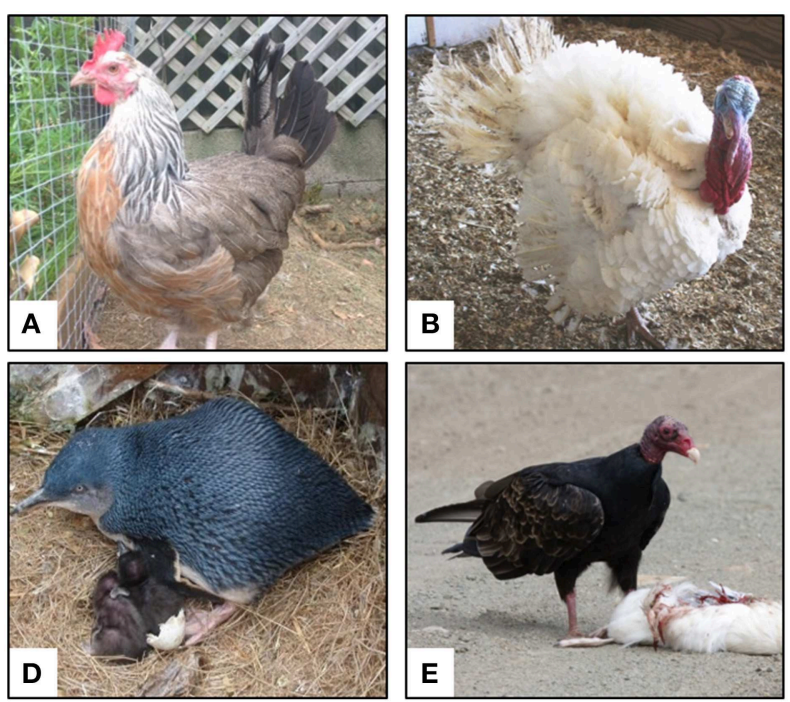
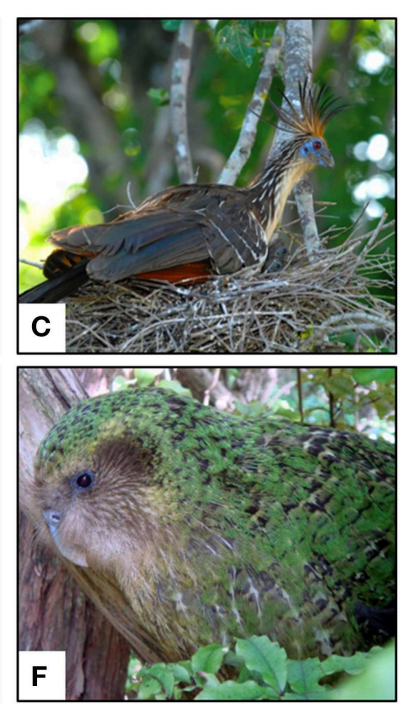

FIGURE 1 | A selection of avians that have been studied in a microbiology context. Chicken (Gallus gallus domesticus), (A); turkey (Meleagris gallopavo), (B); hoatzin (Opisthocomus hoazin), (C); little penguin
(Eudyptula minor), (D); turkey vulture (Cathartes aura), (E); and the kakapo (Strigops habroptilus), (F). All images are used with the authors' permission, as detailed in the Acknowledgments. diet that flying affords, allowing the hoatzin to specifically target higher quality foods with consequent rapid fermentation and optimal digestive efficiency (Grajal et al., 1989). Crop bacteria may also perform another important role for the hoatzin, by degrading toxic polyphenolic compounds which are present in many of the consumed plant species (Domínguez-Bello et al., 1994; Garcia-Amado et al., 2003, 2007). The extent to which the hoatzin relies on behavioral (avoidance) strategies, or its own crop microbiota, to enable its folivorous diet remains uncertain (Jones et al., 2000).

Another ecological niche which exposes the bird to toxic components is that exploited by vultures. Vultures, such as the turkey vulture (Cathartes aura; Figure 1) and black vulture (Coragyps atratus), consume carrion, feeding upon decaying animal carcasses that are in some cases days old. These habits expose vultures to a range of potential pathogens (Marin et al., 2014; Sulzner et al., 2014) as well as bacterial toxins, such as botulinum, produced during tissue breakdown. This is enough to deter most potential consumers, yet vultures are seemingly inured to these compounds. The faces of turkey and black vultures, which are often inserted inside decaying body cavities of vertebrate prey species, contain a highly diverse, yet substantially overlapping microbiota consisting primarily of Actinobacteria, Firmicutes (Bacilli and Clostridia), as well as Beta- and Gammaproteobacteria. The similarity in microbiota between the two vulture species likely reflects the common diets of these co-occurring scavengers (Roggenbuck et al., 2014). Corresponding hindgut samples yielded significantly lower bacterial diversities (though with some overlapping phylotypes), indicating that most diet-derived bacteria do not survive the passage from the mouth to the gut. The hindgut microbiota of both vulture species is dominated by members of only two bacterial classes, Clostridia and Fusobacteria (Roggenbuck et al.,
2014). It is surmised that these two taxa outcompete other bacteria in the vulture hindgut, while the bird can tolerate bacterial toxins in order to exploit their degradation of carrion tissues.

The kakapo (Strigops habroptilus; Figure 1) of New Zealand is the world's heaviest parrot and only flightless parrot. It is also the only parrot that performs a mating ritual known as lek breeding, through which males compete for mates through a characteristic booming call. It is, unfortunately, also one of the world's rarest species, with only 126 individuals confined to three predator-free islands off New Zealand's coast. Like the aforementioned hoatzin, the kakapo is herbivorous, and it has long been speculated that it also performs foregut fermentation (Morton, 1978). However, the two bird species are markedly different when it comes to feeding strategy. The kakapo typically pulls foliage through its beak, sucking out nutrients while leaving the more recalcitrant, fibrous material behind in characteristic "chews" (Oliver, 1955; Horrocks et al., 2008). The requirement for an extensive microbial community to ferment plant material is therefore dramatically reduced, as reflected in recent molecular studies which revealed the kakapo microbiome to typically be dominated (up to $\sim 95 \%$ ) by only two bacterial phylotypes belonging to the genera Escherichia and Streptococcus (Waite et al., 2013, 2014).

The study of microbial diversity and function in avians is a burgeoning field, with recent focus not only on the birds mentioned above, but also others including penguins (Figure 1) and commercially important species such as chickens and turkeys (Figure 1). Unsurprisingly, commercially raised fowl have long been the subject of microbiological investigation, but their microbiology has been reviewed elsewhere (Yeoman et al., 2012; Wei et al., 2013; Oakley et al., 2014; Cox and Dalloul, 2015; Deusch et al., 2015) and is not specifically covered here. 


\section{What do We Know about the Avian Gut Microbiota?}

Much like for other vertebrate hosts, the GI microbiota of avians is dominated by members of the Firmicutes, with Actinobacteria, Bacteroidetes, and Proteobacteria also commonly observed (Figure 2). This broad generalization holds across both herbivores and carnivores, although the relative proportions of these groups can vary substantially. Despite these superficial similarities, the microbiota of avians is somewhat distinct from that of other branches of the tree of life. Hird et al. (2014) compared the microbiota of numerous avians to a larger sequence data set (Ley et al., 2008) and showed that the gut microbiota of avians clustered apart from that of mammals and insects. Performing this analysis with our own aggregation of data also demonstrated this finding (Figure 3, Supplemental Figures S2, S3), with avian samples showing clustering apart from samples obtained from humans and other mammals, insects and fish (ANOSIM, $0.49<R<0.72$ ) but surprisingly weak structuring apart from samples obtained from reptiles (ANOSIM $R=0.12)(p<0.001$ for all comparisons). Among avians, the richness of the microbiota can vary considerably, ranging from dominance by only a handful of phylotypes, as in the case of the kakapo, to a highly diverse community comprising 40 bacterial phyla, as observed for the hoatzin (Godoy-Vitorino et al., 2010) (the hoatzin data were not included in Figure 2 due to differences in the methodology by which they were obtained (PhyloChip microarray vs. nextgeneration sequencing)). For a more detailed description of the microbiota data, including diversity comparisons (with an average of 5.5 bacterial phyla per avian sample), the reader is referred to our recent meta-analysis paper (Waite and Taylor, 2014). The functional role of microbes in the hindgut of birds has historically been an area of interest (Bolton, 1965; Pritchard, 1972; Józefiak et al., 2004), with microbial production of lactate, acetate and other short-chain fatty acids strongly implicated in the health of birds and other vertebrates (Van Der Wielen et al., 2000; Hosseini et al., 2011; Fukuda et al., 2012). More recently, the focus has moved to areas of greater interest in agriculture, predominantly the roles of microbial strains or communities in preventing pathogen colonization and for boosting weight gain (Watkins and Miller, 1983; Jin et al., 1998; Cutler et al., 2005; Torok et al., 2008; Zhang et al., 2011, 2014; Cao et al., 2012; Chen et al., 2013).

Although host genetics clearly influence the human gut microbiota (Goodrich et al., 2014) and evidence exists for the

\section{KEY CONCEPT 2 | Host genetics}

The influence of host genetics on the gut microbiota is an intriguing, and complicated, facet of microbiology. Host genetics have a measurable, albeit subtle, influence on the gut microbiota at both inter-species and withinpopulation resolutions, likely resulting from physiological differences between the guts and immunological profiles of individuals. However, these effects are often overshadowed by other environmental factors, with cohabitation and local diet patterns providing confounding influences.

importance of host-specific factors as determinants of the avian gut microbiota (Zhu et al., 2002; Banks et al., 2009; Benskin et al., 2010; Grond et al., 2014), the scale at which this effect is observed is small compared to that of other factors such as diet (Lozupone et al., 2013; Carmody et al., 2015). A recent analysis by Hird et al.

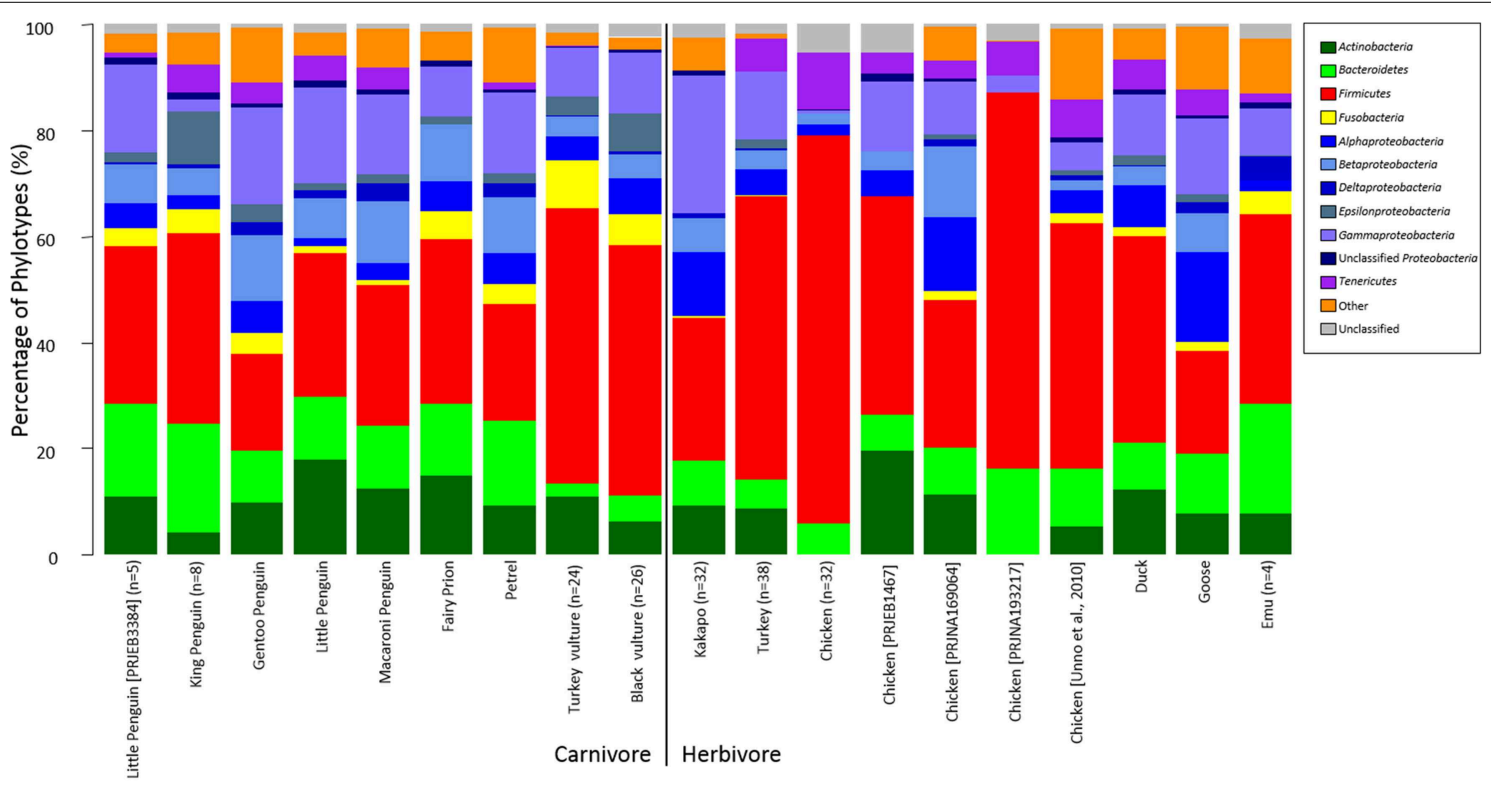

FIGURE 2 | Relative proportions of bacterial phylotypes detected in the avian gut microbiota. Data were processed as per Waite and Taylor (2014). Figure displays the number of genus-level phylotypes detected in each sample, not the relative abundance of these phylotypes. Where studies analyzed multiple individuals, results were averaged across the study with the number of individuals in brackets. Data sources are as detailed in Supplemental Table $\mathbf{S 1 .}$ 


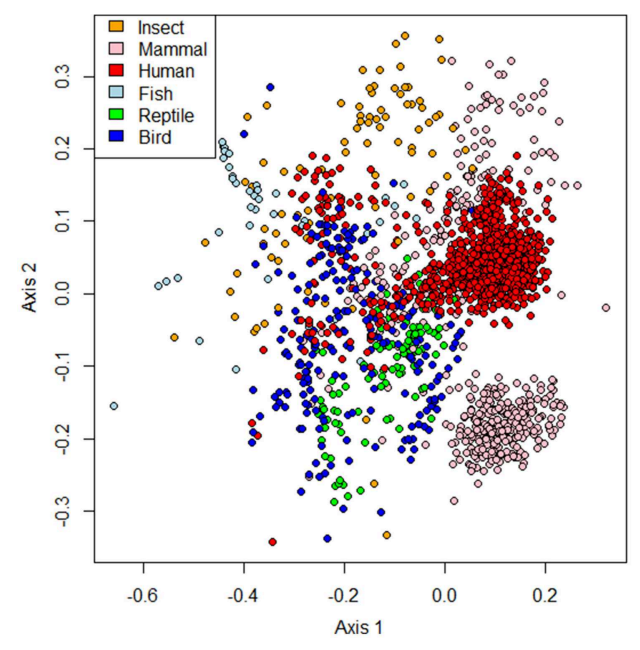

FIGURE 3 | Non-metric multidimensional scaling plots of the avian gut microbiota compared to that of other animal lineages. Data from next-generation amplicon sequencing sources were used. Figure displays NMDS based on unweighted unifrac distance (left, stress $=0.18, R^{2}=0.87$ ) and Jaccard dissimilarity index of genus-level phylotypes (right, stress $=0.19, R^{2}=0.91$ ). Unweighted

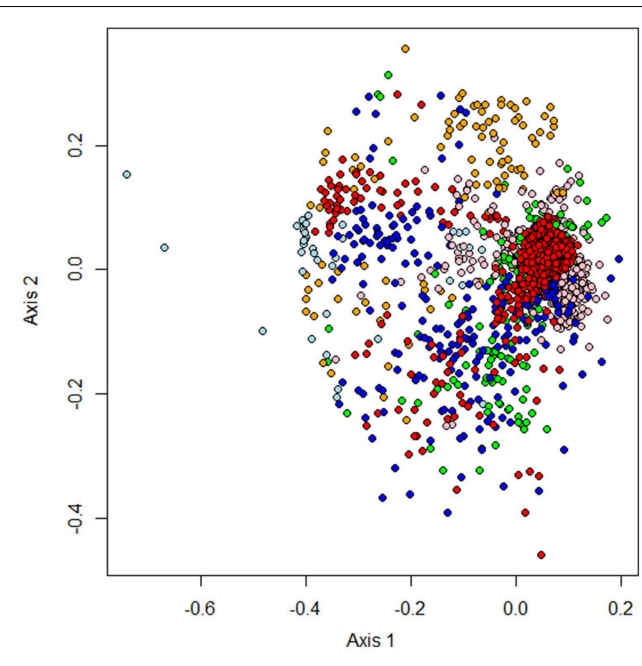

UniFrac distances were inferred through closed-reference OTU picking using QIIME 1.80, and phylotypes were generated using the assign_taxonomy.py script with the Greengenes database (May 2013 release) (Caporaso et al., 2010). Three dimensional representations of the data are provided in Supplemental Figures S2, S3. All data sources are provided in Supplemental Table S2.
(2014) addressed the influence of environmental and host factors on shaping the avian microbiota by comparing fecal microbiota profiles of the cowbird (an avian brood parasite) to those of birds known to host cowbird young. The data obtained showed clearly that location, age and diet all play greater roles in shaping the gut microbiota of cowbirds than the taxonomic identity of the birds studied. A similar result was reported for members of the Paridae in an earlier study (Lucas and Heeb, 2005) and has also been shown for chickens raised in captivity (Stanley et al., 2013). While gut microbes convey benefits to their hosts in a variety of ways (Pritchard, 1972; Domínguez-Bello et al., 1993; Preest et al., 2003; Shawkey et al., 2007; Burtt et al., 2011), the findings of Hird and colleagues suggest that the microbiota is more a product of the environment than a trait of the bird itself. Our own aggregation of data support this finding, with occurrence of bacterial phyla (Actinobacteria, Fusobacteria) and classes (Alpha-, Beta-, Delta-, and Epsilonproteobacteria) varying between different studies of the same host organism (Figure 2, chicken). Our meta-analysis of amplicon sequence data also revealed study origin to have

\section{KEY CONCEPT 3 | Amplicon sequencing}

A generic term to describe the PCR amplification, and subsequent sequencing by one of the "next-generation" sequencing technologies, of genes from extracted microbial DNA. Amplicon sequencing most commonly utilizes $16 \mathrm{~S}$ ribosomal RNA (rRNA) genes, as these are conserved in all bacteria and archaea (eukaryotes contain the homologous 18S rRNA gene). The analysis of rRNA genes via sequencing has been a cornerstone of microbial ecology for more than two decades, while functional genes (e.g., encoding for specific enzymes) can also be targeted with the amplicon sequencing approach.

greater explanatory power than biological variables, such as diet, when investigating the avian microbiota (Waite and Taylor, 2014). The interplay between environmental factors and host genetics in shaping the microbiome has been reported for other vertebrates (Benson et al., 2010; Campbell et al., 2012; Stanley et al., 2013), although care must be taken when dissecting genetic effects and the role of maternal inoculation of the microbiota (Spor et al., 2011).

An interesting aspect of avian microbiology that has only recently come to light is the potential role of Fusobacteria in the guts of carnivorous birds. While members of the Fusobacteria are often studied in the context of pathogenicity, recent analyses of the vulture microbiota have revealed abundant populations of Fusobacteria that appear to be beneficial, or at the very least harmless, to the host bird (Roggenbuck et al., 2014). While Firmicutes, Bacteroidetes and Proteobacteria are the most consistently observed bacterial phyla across the animal gut microbiota, a rich community of Fusobacteria has frequently been reported in the guts of carnivorous and omnivorous avians. These include close relatives of the human pathogens Fusobacterium nucleatum and F. necrophorum, while the avian pathogen Streptobacillus moniliformis (also a member of the phylum Fusobacteria) was detected in some penguin samples. Up to one third of the vulture gut microbiota, and over half of the penguin microbiota, can consist of Fusobacteria (Dewar et al., 2013, 2014a; Roggenbuck et al., 2014; Vela et al., 2014), with F. mortiferum predominating among Fusobacteria within the vulture microbiota. Fusobacteria are also observed at a lower abundance in other carnivorous seabirds and the omnivorous bustard (Dewar et al., 2014b; Shabbir et al., 2014), and have been reported in the guts of some non-mammalian carnivores (Keenan et al., 2013; Nelson et al., 2013), although a consistent pattern has not been observed in mammals (Ley et al., 2008; Swanson et al., 2011; Nelson et al., 2013). While the consistent appearance of Fusobacteria in the avian microbiome is an interesting avenue for 
further study, the potential role of this phylum in avian nutrition requires further analysis, as does the occurrence of Fusobacteria in captive avians (Figure 2).

\section{A Look to the Future}

The gut microbiology of humans and other vertebrates has exploded as a discipline over the past decade, driven by technological advances and an increased appreciation of the vital roles played by the gut microbiome in animal health. Although study of the avian microbiota has arguably lagged behind that of some other host organisms, this gap is closing rapidly. As discussed within these pages, certain key taxasuch as the chicken, turkey, hoatzin, and kakapo-have received considerable research attention from microbiologists, and it is to be hoped that our current knowledge of the avian microbiota will soon be extended to encompass many of the "missing" branches of the bird tree of life (Figure 4). Expanding the knowledge on any avian lineage will be of value in resolving high-level patterns of the influence of diet and lifestyle on the gut microbiota. A lineage that we feel would be of great interest is the hummingbird, which possesses the fastest metabolism among homeothermic animals (Suarez, 1992) and relies on a diet primarily of nectar supplemented with arthropods (Brice, 1992; Yanega and Rhubega, 2004; Powers et al., 2010). As an adaptation to the extreme levels of sugar ingested, hummingbirds possess extremely potent sucrase (Martínez Del Rio, 1990) and are able to survive in a constant state of hyperglycemia (Beuchat and Chong, 1998). Although some study of bacterial activity in hummingbirds has been performed (Preest et al., 2003), deeper analysis of this community would greatly aid our understanding of not only gut bacteria in general but specifically life in an osmotically challenging environment.

Despite containing the same core phyla as the mammalian gut microbiota, the "typical" microbiota of avians is clearly distinct from that of mammals and insects (Hird et al., 2014) and analysis of full-length 16S rRNA genes often yields sequences that diverge heavily from previously obtained bacterial sequences (Zhu et al., 2002; Bjerrum et al., 2006; Godoy-Vitorino et al., 2008, 2010). The pace at which $16 \mathrm{~S}$ rRNA gene information has grown has left many other aspects of microbial genomics and ecology behind. The content of the publicly available 16S rRNA gene sequences in the Greengenes database outnumbers prokaryotic type strains by over 40:1, and prokaryotic genomes by about 20:1 (Kyrpides et al., 2014). While some inferences about the functional roles of microbes associated with the avian GI tract can be made using predictive software such as PICRUSt (Langille et al., 2013), much of the actual function of these communities remains unclear, especially when considering the significant evolutionary specialization which gut-associated bacteria often undergo (Comstock and Coyne, 2003; Xu et al., 2003; Meinl et al., 2009; Frese et al., 2011; Foley et al., 2013). The suite of meta-"omics" techniques offers partial solutions to this issue obviating, or in some cases aiding, the need for cultivation and potentially providing new insights into the communitylevel function and ecological interactions in the avian gut. While not related to the study of avians, metagenomics has previously been applied to tailor cultivation conditions in order to isolate previous uncultivated bacteria (Tyson et al., 2004, 2005). One can easily envisage the complementary application of metagenomics, metatranscriptomics and metaproteomics in order to elucidate the functional potential, gene expression and protein production, respectively, of the microbial community associated with an avian host. Such integrated approaches have been applied to gut environments to some extent (Pérez-Cobas et al., 2013; Kato et al., 2014) and, when used in combination with recently acquired bird genome data (Jarvis et al., 2014), would offer unprecedented insights into avian-microbe interactions.

Our own studies of the kakapo microbiome (Waite et al., 2013, 2014) have identified an area of potential wider research and applied interest, namely the use of microbial ecology approaches to aid in avian conservation. To use the kakapo as a case in point, characterization of the indigenous microbiota should facilitate the detection of microbial dysbiosis and, potentially, the identification of invading pathogenic species, while longitudinal studies have allowed the effects of human intervention and intrinsic host characteristics on the gut microbiota to be teased apart (Waite et al., 2014). Such an approach should be equally beneficial for the conservation of any intensively managed, endangered bird.

Studying the impact of environmental factors on the avian gut microbiota highlights another area in which avian microbiology is lacking, namely the existence of a global, unified initiative using a common methodology to resolve large-scale patterns in microbial distribution and function. The recently completed Human Microbiome Project (Human Microbiome Project Consortium, 2012; Human Microbiome Project, 2014) represented a landmark in microbiology, bringing together research from a number of institutions and research groups to tackle a series of overarching questions. Following in the footsteps of the HMP, a range of projects have been enacted to address areas of ecological and medical microbiology in a standardized manner. The Earth Microbiome Project (Gilbert et al., 2014), Hospital Microbiome Project (http://hospitalmicrobiome.com/) and 1000 Springs project (http://www.1000springs.org.nz/) all aim to study large sources of data using a common laboratory and bioinformatics approach in order to reduce methodological artifacts, which are known to contribute large sources of bias to studies. Other studies have begun to combine genome-wide and microbiomewide association studies to comprehensively identify the genetic pathways through which vertebrate hosts influence the microbiota (Benson, 2014).

In summary, while the avian microbiota is an area of microbiology of great economic importance and scientific interest, the field has arguably not advanced as quickly as some other areas of microbiology. While trends seen in avian microbiology do appear to reflect those seen in other vertebrates there are key areas of the avian microbiota that distinguish it from that of mammals and reptiles. The last decade has seen a massive leap forward in the technology available to microbiologists and while the avian microbiota has lagged behind other vertebrates, interest appears to be growing in this area of microbiology and many novel avenues of study exist within avian microbiology. 


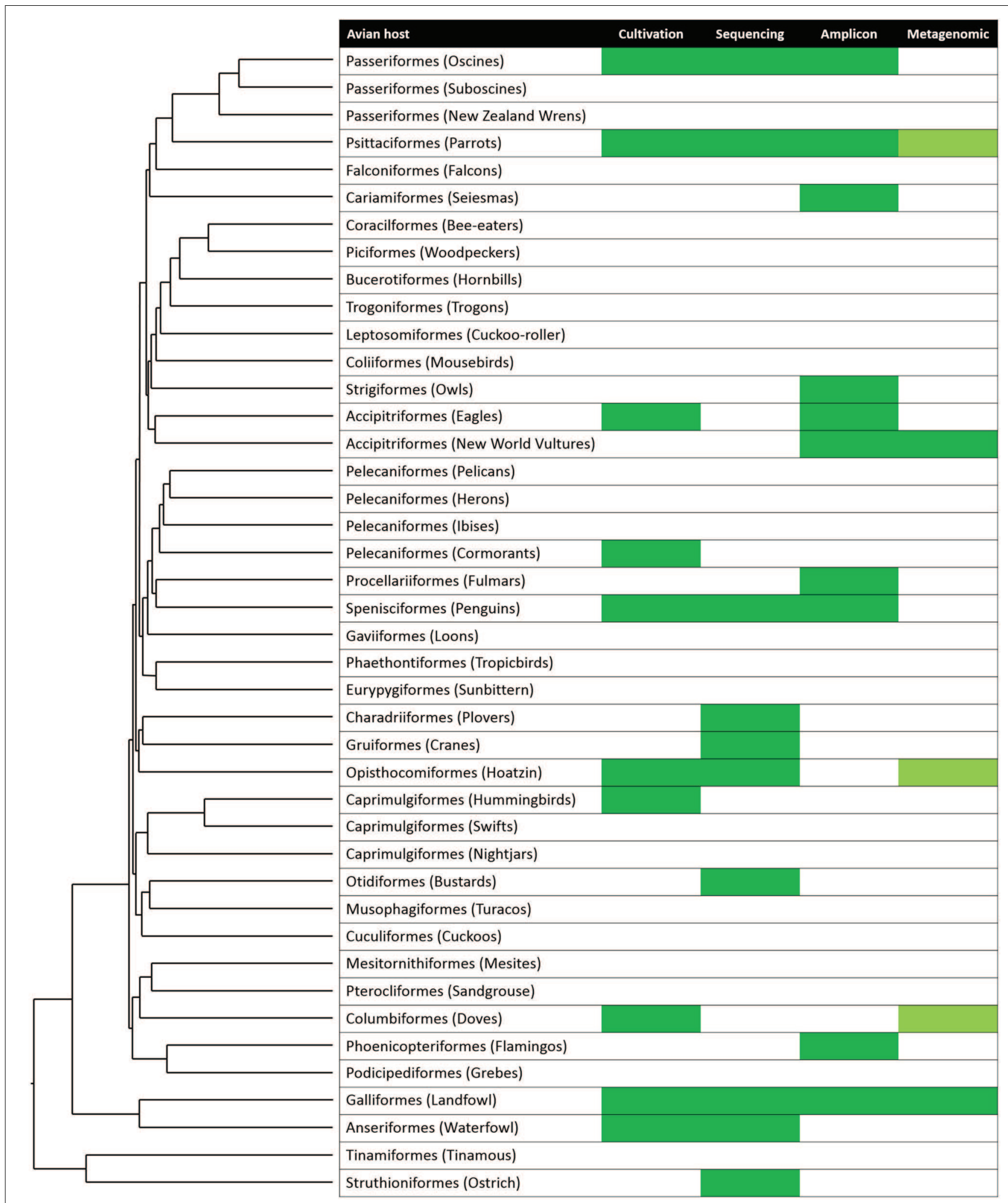

FIGURE 4 | Coverage of microbiological representation across avian lineages. Two studies have been performed on avian orders with no representation in the displayed phylogeny (emu, Bennett et al., 2013; cormorant, Tausova et al., 2012). The microbiota of several species has been studied using molecular techniques other than sequence analysis (Lucas and Heeb, 2005; Ruiz-Rodríguez et al., 2009). Pale green indicates data that are available on online repositories, but currently unpublished. Figure modified from Jarvis et al. (2014); reprinted with permission from AAAS and the author. 


\section{Acknowledgments}

We gratefully acknowledge Meagan Dewar (penguin), Gavin Lear (chicken), Tim Johnson and Lara Durben (turkey), Kevin Cole (turkey vulture), Jacqueline Beggs (kakapo), and Filipa GodoyVitorino and Fabian Michellangeli (hoatzin) for providing the images featured in Figure 1. We are also grateful to Erich Jarvis for providing the avian phylogenetic tree in Figure 4.

\section{Supplementary Material}

The Supplementary Material for this article can be found online at: http://journal.frontiersin.org/article/10.3389/fmicb. 2015.00673

Supplemental Figure S1 | Cumulative number of 16S rRNA gene data sets from published research investigating the avian microbiota. Red line denotes the addition of 16S rRNA gene data obtained from next-generation sequencing platforms to the main data set. Counts incorporating these sequence read archive (SRA) data (red line) are inclusive of full-length 16S rRNA gene sequence data. Published studies were identified using the SCOPUS database, and additional SRA data through the NCBI SRA website using the search string "(bird OR avian OR aves) AND microb*." All returned studies were manually examined to ensure they had submitted sequence data to a publically available repository.

Supplemental Figure S2 | Three dimensional non-metric multidimensional scaling plot of the unweighted UniFrac distances between samples. Unweighted UniFrac distances were inferred through closed-reference OTU picking using QIIME 1.80 (Caporaso et al., 2010) against the Greengenes 16S rRNA gene database (May 2013 release). Plot was visualized using the "rgl" package in $\mathrm{R}$.

Supplemental Figure S3 | Three dimensional non-metric multidimensional scaling plot of the binary Jaccard distances of genus-level phylotypes between samples. Phylotypes were constructed following classification using the assign_taxonomy.py script in QIIME 1.80 (Caporaso et al., 2010) against the Greengenes 16S rRNA gene database (May 2013 release). Plot was visualized using the "rgl" package in $\mathrm{R}$.

Supplemental Table S1 | Summary of published sequence data obtained from molecular analysis of avian samples. Asterisk $(*)$ denotes a study that analysed the bacterial communities associated with multiple species of birds. Cultivation studies are only included where they utilised non-selective cultivation conditions (e.g. did not select for antibiotic-resistant bacterial strains). Where publication details associated with a data set could not be obtained the NCBI Sequence Read Archive BioProject accession is provided.

Supplemental Table S2 | 16S rRNA amplicon data sources for comparative microbiota analysis. All data were quality filtered as described in Waite and Taylor (2014) prior to analysis.

\section{References}

Angelakis, E., and Raoult, D. (2010). The increase of Lactobacillus species in the gut flora of newborn broiler chicks and ducks is associated with weight gain. PLoS ONE 5:e10463. doi: 10.1371/journal.pone.0010463

Banks, J. C., Cary, S. C., and Hogg, I. D. (2009). The phylogeography of Adelie penguin faecal flora. Environ. Microbiol. 11, 577-588. doi: 10.1111/j.14622920.2008.01816.x

Barnes, E. M. (1972). The avian intestinal flora with particular reference to the possible ecological significance of the cecal anaerobic bacteria. Am. J. Clin. Nutr. 25, 1475-1479.

Bennett, D. C., Tun, H. M., Kim, J. E., Leung, F. C., and Cheng, K. M. (2013). Characterization of cecal microbiota of the emu (Dromaius novaehollandiae). Vet. Microbiol. 166, 304-310. doi: 10.1016/j.vetmic.2013.05.018

Benskin, C. M., Rhodes, G., Pickup, R. W., Wilson, K., and Hartley, I. R. (2010). Diversity and temporal stability of bacterial communities in a model passerine bird, the zebra finch. Mol. Ecol. 19, 5531-5544. doi: 10.1111/j.1365294X.2010.04892.x

Benson, A. (2014). "MWAS and GWAS studies to define associations between host genetics, microbiome composition, and EHEC colonization," in STEP CAP Annual Conference (Lincoln, NE).

Benson, A. K., Kelly, S. A., Legge, R., Ma, F., Low, S. J., Kim, J., et al. (2010). Individuality in gut microbiota composition is a complex polygenic trait shaped by multiple environmental and host genetic factors. Proc. Natl. Acad. Sci. U.S.A. 107, 18933-18939. doi: 10.1073/pnas. 1007028107

Beuchat, C. A., and Chong, C. R. (1998). Hyperglycemia in hummingbirds and its consequences for hemoglobin glycation. Comp. Biochem. Physiol. A Mol. Integr. Physiol. 120, 409-416. doi: 10.1016/S1095-6433(98)10039-9

Bjerrum, L., Engberg, R. M., Leser, T. D., Jensen, B. B., Finster, K., and Pedersen, K. (2006). Microbial community composition of the ileum and cecum of broiler chickens as revealed by molecular and culture-based techniques. Poult. Sci. 85, 1151-1164. doi: 10.1093/ps/85.7.1151

Blanco, G., Lemus, J. A., and Grande, J. (2006). Faecal bacteria associated with different diets of wintering red kites: influence of livestock carcass dumps in microflora alteration and pathogen acquisition. J. Appl. Ecol. 43, 990-998. doi: 10.1111/j.1365-2664.2006.01200.x

Bolton, W. (1965). Digestion in the crop of the fowl. Br. Poult. Sci. 6, 97-102. doi: $10.1080 / 00071666508415561$

Boucias, D. G., Cai, Y., Sun, Y., Lietze, V.-U., Sen, R., Raychoudhury, R., et al. (2013). The hindgut lumen prokaryotic microbiota of the termite Reticulitermes flavipes and its responses to dietary lignocellulose composition. Mol. Ecol. 22, 1836-1853. doi: $10.1111 / \mathrm{mec} .12230$

Brice, A. T. (1992). The essentiality of nectar and arthropods in the diet of the Anna's hummingbird (Calypte anna). Comp. Biochem. Physiol. A Mol. Integr. Physiol. 101, 151-155. doi: 10.1016/0300-9629(92)90643-5

Burtt, E. H., Schroeder, M. R., Smith, L. A., Sroka, J. E., and McGraw, K. J. (2011). Colourful parrot feathers resist bacterial degradation. Biol. Lett. 7, 214-216. doi: 10.1098/rsbl.2010.0716

Campbell, J. H., Foster, C. M., Vishnivetskaya, T., Campbell, A. G., Yang, Z. K., Wymore, A., et al. (2012). Host genetic and environmental effects on mouse intestinal microbiota. ISME J. 6, 2033-2044. doi: 10.1038/ismej.2012.54

Cao, G. T., Xiao, Y. P., Yang, C. M., Chen, A. G., Liu, T. T., Zhou, L., et al. (2012). Effects of Clostridium butyricum on growth performance, nitrogen metabolism, intestinal morphology and cecal microflora in broiler chickens. J. Anim. Vet. Adv. 11, 2665-2671. doi: 10.3923/javaa.2012.2665.2671

Caporaso, J. G., Kuczynski, J., Stombaugh, J., Bittinger, K., Bushman, F. D., Costello, E. K., et al. (2010). QIIME allows analysis of highthroughput community sequencing data. Nat. Methods 7, 335-336. doi: 10.1038/nmeth.f.303

Carmody, R. N., Gerber, G. K., Luevano, J. M., Gatti, D. M., Somes, L., Svenson, K. L., et al. (2015). Diet dominates host genotype in shaping the murine gut microbiota. Cell Host Microbe 17, 72-84. doi: 10.1016/j.chom.2014.11.010

Chen, C. Y., Yu, C., Chen, S. W., Chen, B. J., and Wang, H. T. (2013). Effect of yeast with bacteriocin from rumen bacteria on growth performance, caecal flora, caecal fermentation and immunity function of broiler chicks. J. Agric. Sci. 151, 287-297. doi: 10.1017/S0021859612000421

Comstock, L. E., and Coyne, M. J. (2003). Bacteroides thetaiotaomicron: a dynamic, niche-adapted human symbiont. Bioessays 25, 926-929. doi: 10.1002/bies.10350

Cox, C. M., and Dalloul, R. A. (2015). Immunomodulatory role of probiotics in poultry and potential in ovo application. Benef. Microbes 6, 45-52. doi: 10.3920/BM2014.0062

Cutler, S. A., Rasmussen, M. A., Hensley, M. J., Wilhelms, K. W., Griffith, R. W., and Scanes, C. G. (2005). Effects of Lactobacilli and lactose on Salmonella typhimurium colonisation and microbial fermentation in the crop of the young turkey. Br. Poult. Sci. 46, 708-716. doi: 10.1080/00071660500 393694 
Damaré, J. M., Hussong, D., Weiner, R. M., and Colwell, R. R. (1979). Aerobic and facultatively anaerobic bacteria associated with the gut of Canada geese (Branta canadensis) and whistling swans (Cygnus columbianus columbianus). Appl. Environ. Microbiol. 38, 258-266.

Danzeisen, J. L., Calvert, A. J., Noll, S. L., McComb, B., Sherwood, J. S., Loque, C. M., et al. (2013). Succession of the turkey gastrointestinal bacterial microbiome related to weight gain. PeerJ. 1:e237. doi: 10.7717/pe erj. 237

Deusch, S., Tilocca, B., Camarinha-Silva, A., and Seifert, J. (2015). News in livestock research - use of Omics-technologies to study the microbiota in the gastrointestinal tract of farm animals. Comput. Struct. Biotechnol. J. 13, 55-63. doi: 10.1016/j.csbj.2014.12.005

Dewar, M. L., Arnould, J. P., Dann, P., Trathan, P., Groscolas, R., and Smith, S. (2013). Interspecific variations in the gastrointestinal microbiota in penguins. Microbiologyopen 2, 195-204. doi: 10.1002/mbo3.66

Dewar, M. L., Arnould, J. P., Krause, L., Trathan, P., Dann, P., and Smith, S. C. (2014a). Influence of fasting during moult on the faecal microbiota of penguins. PLoS ONE 9:e99996. doi: 10.1371/journal.pone.0099996

Dewar, M. L., Arnould, J. P. Y., Krause, L., Dann, P., and Smith, S. C. (2014b). Interspecific variations in the faecal microbiota of Procellariiform seabirds. FEMS Microbiol. Ecol. 89, 47-55. doi: 10.1111/1574-6941.12332

Dietrich, C., Köhler, T., and Brune, A. (2014). The cockroach origin of the termite gut microbiota: patterns in bacterial community structure reflect major evolutionary events. Appl. Environ. Microbiol. 80, 2261-2269. doi: 10.1128/AEM.04206-13

Domínguez-Bello, M. G., Lovera, M., Suarez, P., and Michelangeli, F. (1993). Microbial digestive symbionts of the crop of the hoatzin (Opisthocomus hoazin): an avian foregut fermenter. Physiol. Zool. 66, 374-383.

Domínguez-Bello, M. G., Michelangeli, F., Ruiz, M. C., Garda, A., and Rodriguez, E. (1994). Ecology of the folivorous hoatzin (Opisthocomus hoazin) on the Venezuelan plains. Auk 111, 643-651.

Engel, P., and Moran, N. A. (2013). The gut microbiota of insects-diversity in structure and function. FEMS Microbiol. Rev. 37, 699-735. doi: 10.1111/15746976.12025

Foley, S. L., Johnson, T. J., Ricke, S. C., Nayak, R., and Danzeisen, J. L. (2013). Salmonella pathogenicity and host adaptation in chicken-associated serovars. Microbiol. Mol. Biol. Rev. 77, 582-607. doi: 10.1128/MMBR.00015-13

Ford, D. J., and Coates, M. E. (1971). Absorption of glucose and vitamins of the B complex by germ-free and conventional chicks. Proc. Nutr. Soc. 30, 10A-11A.

Frese, S. A., Benson, A. K., Tannock, G. W., Loach, D. M., Kim, J., Zhang, M., et al. (2011). The evolution of host specialization in the vertebrate gut symbiont Lactobacillus reuteri. PLoS Genet. 7:e1001314. doi: 10.1371/journal.pgen.1001314

Fukuda, S., Toh, H., Taylor, T. D., Ohno, H., and Hattori, M. (2012). Acetateproducing bifidobacteria protect the host from enteropathogenic infection via carbohydrate transporters. Gut Microbes 3, 449-454. doi: 10.4161/gmic.21214

Garcia-Amado, M. A., Gueneau, P., Michelangeli, F., and Domínguez-Bello, M. G. (2003). Rate of detoxification of Quillaja saponins by crop bacteria from Opisthocomus hoazin is increased in the presence of methanogenic bacteria. Trop. Subtrop. Agroecosyst. 3, 595-598.

Garcia-Amado, M. A., Michelangeli, F., Gueneau, P., Perez, M. E., and DomínguezBello, M. G. (2007). Bacterial detoxification of saponins in the crop of the avian foregut fermenter Opisthocomus hoazin. J. Anim. Feed Sci. 16, 82-85.

Gilbert, J. A., Jansson, J. K., and Knight, R. (2014). The Earth Microbiome project: successes and aspirations. BMC Biol. 12:69. doi: 10.1186/s12915-014-0069-1

Gill, F., and Donsker, D. (2015). IOC World Bird List (v 5.1) (Online). Available online at: http://www.worldbirdnames.org/ (Accessed January 25, 2015).

Godoy-Vitorino, F., Goldfarb, K. C., Brodie, E. L., Garcia-Amado, M. A., Michelangeli, F., and Domínguez-Bello, M. G. (2010). Developmental microbial ecology of the crop of the folivorous hoatzin. ISME J. 4, 611-620. doi: 10.1038/ismej.2009.147

Godoy-Vitorino, F., Goldfarb, K. C., Karaoz, U., Leal, S., Garcia-Amado, M. A., Hugenholtz, P., et al. (2012). Comparative analyses of foregut and hindgut bacterial communities in hoatzins and cows. ISME J. 6, 531-541. doi: 10.1038/ismej.2011.131

Godoy-Vitorino, F., Ley, R. E., Gao, Z., Pei, Z., Ortiz-Zuazaga, H., Pericchi, L. R., et al. (2008). Bacterial community in the crop of the hoatzin, a neotropical folivorous flying bird. Appl. Environ. Microbiol. 74, 5905-5912. doi: 10.1128/AEM.00574-08

Gong, J., Weiduo, S., Forster, R. J., Huang, R., Yu, H., Yin, Y., et al. (2007). $16 \mathrm{~S}$ rRNA gene-based analysis of mucosa-associated bacterial community and phylogeny in the chicken gastrointestinal tracts: from crops to ceca. FEMS Microbiol. Ecol. 59, 147-157. doi: 10.1111/j.1574-6941.2006.00193.x

Goodrich, J. K., Waters, J. L., Poole, A. C., Sutter, J. L., Koren, O., Blekhman, R., et al. (2014). Human genetics shape the gut microbiome. Cell 159, 789-799. doi: 10.1016/j.cell.2014.09.053

Grajal, A., Strahl, S. D., Pabra, R., Dominguez, M. G., and Neher, A. (1989). Foregut fermentation in the hoatzin, a neotropical leaf-eating bird. Science 245, 1236-1238. doi: 10.1126/science.245.4923.1236

Grond, K., Ryu, H., Baker, A. J., Santo Domingo, J. W., and Buehler, D. M. (2014). Gastro-intestinal microbiota of two migratory shorebird species during spring migration staging in Delaware Bay, USA. J. Ornithol. 155, 969-977. doi: 10.1007/s10336-014-1083-3

Hammons, S., Oh, P. L., Martínez, I., Clark, K., Schlegel, V. L., Sitorius, E., et al. (2010). A small variation in diet influences the Lactobacillus strain composition in the crop of broiler chickens. Syst. Appl. Microbiol. 33, 275-281. doi: 10.1016/j.syapm.2010.04.003

Hildebrand, F., Nguyen, T. L. A., Brinkman, B., Yunta, R. G., Cauwe, B., Vandenabeele, P., et al. (2013). Inflammation-associated enterotypes, host genotype, cage and inter-individual effects drive gut microbiota variation in common laboratory mice. Genome Biol. 14:R4. doi: 10.1186/gb-2013-14-1-r4

Hird, S. M., Carsten, B. C., Cardiff, S. W., Dittmann, D. L., and Brumfield, R. T. (2014). Sampling locality is more detectable than taxonomy or ecology in the gut microbiota of the brood-parasitic Brown-headed Cowbird (Molothrus ater). PeerJ. 2:e321. doi: 10.7717/peerj.321

Horrocks, M., Salter, J., Braggins, J., Nichol, S., Moorhouse, R., and Elliott, G. (2008). Plant microfossil analysis of coprolites of the critically endangered kakapo (Strigops habroptilus) parrot from New Zealand. Rev. Palaeobot. Palynol. 149, 229-245. doi: 10.1016/j.revpalbo.2007.12.009

Hosseini, E., Grootaert, C., Verstraete, W., and Van Der Wiele, T. (2011). Propionate as a health-promoting microbial metabolite in the human gut. Nutr. Rev. 69, 245-258. doi: 10.1111/j.1753-4887.2011.00388.x

Human Microbiome Project Consortium. (2012). A framework for human microbiome research. Nature 486, 215-221. doi: 10.1038/nature11209

Human Microbiome Project. (2014). Human Microbiome Project (Online). Division of Program Coordination, Planning, and Strategic Initiatives, National Institutes of Health. Available online at: http://commonfund.nih.gov/hmp/ index (Accessed February 2, 2015).

Janczyk, P., Halle, B., and Souffrant, W. B. (2009). Microbial community composition of the crop and ceca contents of laying hens fed diets supplemented with Chlorella vulgaris. Poult. Sci. 88, 2324-2332. doi: $10.3382 /$ ps.2009-00250

Jansson, D. S., Fellström, C., and Johansson, K.-E. (2008). Intestinal spirochetes isolated from wild-living jackdaws, hooded crows and rooks (genus Corvus): provisionally designated "Brachyspira corvi" sp. nov. Anaerobe 14, 287-295. doi: 10.1016/j.anaerobe.2008.09.002

Jarvis, E. D., Mirarab, S., Aberer, A. J., Li, B., Houde, P., Li, C., et al. (2014). Wholegenome analyses resolve early branches in the tree of life of modern birds. Science 346, 1320-1331. doi: 10.1126/science. 1253451

Jin, L. Z., Ho, Y. W., Abdullah, N., Ali, M. A., and Jalaludin, S. (1998). Effects of adherent Lactobacillus cultures on growth, weight of organs and intestinal microflora and volatile fatty acids in broilers. Anim. Feed Sci. Technol. 70, 197-209. doi: 10.1016/S0377-8401(97)00080-1

Jones, R. J., Garcia-Amado, M. A., and Domínguez-Bello, M. G. (2000). Comparison of the digestive ability of crop fluid from the folivorous Hoatzin (Opisthocomus hoazin) and cow rumen fluid with seven tropical forages. Anim. Feed Sci. Technol. 87, 287-296. doi: 10.1016/S0377-8401(00)00199-1

Józefiak, D., Rutkowski, A., and Martin, S. A. (2004). Carbohydrate fermentation in the avian ceca: a review. Anim. Feed Sci. Technol. 113, 1-15. doi: 10.1016/j.anifeedsci.2003.09.007

Kaltenpoth, M., and Steiger, S. (2014). Unearthing carrion beetles' microbiome: characterization of bacterial and fungal hindgut communities across the Silphidae. Microb. Ecol. 23, 1251-1267. doi: 10.1111/mec.12469

Kato, T., Fukuda, S., Fujiwara, A., Suda, W., Hattori, M., Kikuchi, J., et al. (2014). Multiple omics uncovers host-gut 
microbial mutualism during prebiotic fructooligosaccharide supplementation. DNA Res. 21, 469-480. doi: 10.1093/dnares/ dsu013

Keenan, S. W., Engel, A. S., and Elsey, R. M. (2013). The alligator gut microbiome and implications for archosaur symbioses. Sci. Rep. 3:2877. doi: $10.1038 /$ srep02877

Klomp, J. E., Murphy, M. T., Smith, S. B., McKay, J. E., Ferrera, I., and Reysenbach, A. L. (2008). Cloacal microbial communities of female spotted towhees Pipilo maculatus: microgeographic variation and individual sources of variability. J. Avian Biol. 39, 530-538. doi: 10.1111/j.0908-8857.2008.04333.x

Kurzak, P., Ehrmann, M. A., and Vogel, R. F. (1998). Diversity of lactic acid bacteria associated with ducks. Syst. Appl. Microbiol. 21, 588-592. doi: 10.1016/S0723-2020(98)80071-4

Kyrpides, N. C., Hugenholtz, P., Eisen, J. A., Woyke, T., Göker, M., Parker, C. T., et al. (2014). Genomic encyclopedia of bacteria and archaea: sequencing a myriad of type strains. PLoS Biol. 12:e1001920. doi: 10.1371/journal.pbio.1001920

Langille, M. G. I., Zaneveld, J., Caporaso, J. G., McDonald, D., Knights, D., Reyes, J. A., et al. (2013). Predictive functional profiling of microbial communities using 16S rRNA marker gene sequences. Nat. Biotechnol. 31, 814-821. doi: $10.1038 /$ nbt.2676

Ley, R. E., Hamady, M., Lozupone, C., Turnbaugh, P. J., Ramey, R. R., Bircher, J. S., et al. (2008). Evolution of mammals and their gut microbes. Science 320 , 1647-1651. doi: 10.1126/science. 1155725

Lozupone, C., Stombaugh, J., González, A., Ackerman, G., Wendel, D., VáquezBaeza, Y., et al. (2013). Meta-analyses of studies of the human microbiota. Genome Res. 23, 1704-1714. doi: 10.1101/gr.151803.112

Lu, J., and Domingo, J. S. (2008). Turkey fecal microbial community structure and functional gene diversity revealed by $16 \mathrm{~S}$ rRNA gene and metagenomic sequences. J. Microbiol. 46, 469-477. doi: 10.1007/s12275-008-0117-z

Lu, J., Idris, U., Harmon, B., Hofacre, C., Maurer, J. J., and Lee, M. D. (2003). Diversity and succession of the intestinal bacterial community of the maturing broiler chicken. Appl. Environ. Microbiol. 69, 6816-6824. doi: 10.1128/AEM.69.11.6816-6824.2003

Lu, J., Santo Domingo, J. W., Hill, S., and Edge, T. A. (2009). Microbial diversity and host-specific sequences of Canada goose feces. Appl. Environ. Microbiol. 75, 5919-5926. doi: 10.1128/AEM.00462-09

Lu, J., Santo-Domingo, J. W., Lamendella, R., Edge, T., and Hill, S. (2008). Phylogenetic diversity and molecular detection of bacteria in gull feces. Appl. Environ. Microbiol. 74, 3969-3976. doi: 10.1128/AEM.00019-08

Lucas, F. S., and Heeb, P. (2005). Environmental factors shape cloacal bacterial assemblages in great tit Parus major and blue tit $P$. caeruleus nestlings. J. Avian Biol. 36, 510-516. doi: 10.1111/j.0908-8857.2005.03479.x

Marin, C., Palomeque, M.-D., Marco-Jiménez, F., and Vega, S. (2014). Wild griffon vultures (Gyps fulvus) as a source of Salmonella and Campylobacter in eastern Spain. PLoS ONE 9:e94191. doi: 10.1371/journal.pone.0094191

Martínez Del Rio, C. (1990). Dietary, phylogenetic, and ecological correlates of intestinal sucrase and maltase activity in birds. Physiol. Zool. 63, 987-1011.

Matsui, H., Kato, Y., Chikaraishi, T., Moritani, M., Ban-Tokuda, T., and Wakita, M. (2010). Microbial diversity in ostrich ceca as revealed by $16 \mathrm{~S}$ ribosomal RNA gene clone library and detection of novel Fibrobacter species. Anaerobe 16, 83-93. doi: 10.1016/j.anaerobe.2009.07.005

McKnite, A. M., Perez-Munoz, M. E., Lu, L., Williams, E. G., Brewer, S., Andreux, P. A., et al. (2011). Murine gut microbiota is defined by host genetics and modulates variation of metabolic traits. PLoS ONE 7:e39191. doi: 10.1371/journal.pone.0039191

McNab, J. M. (1973). The avian caeca: a review. Worlds Poult. Sci. J. 29, 251-263. doi: 10.1079/WPS19730014

Mead, G. C. (1989). Microbes of the avian cecum: types present and substrates utilized. J. Exp. Zool. 252, 48-54. doi: 10.1002/jez.1402520508

Meinl, W., Sczesny, S., Brigelius-Flohé, R., Blaut, M., and Glatt, H. (2009). Impact of gut microbiota on intestinal and hepatic levels of phase 2 xenobioticmetabolizing enzymes in the rat. Drug Metab. Dispos. 37, 1179-1186. doi: 10.1124/dmd.108.025916

Morton, E. S. (1978). Avian arboreal folivores: why not? Ecol. Arboreal Folivores. 123-130.

Muegge, B. D., Kuczynski, J., Knights, D., Clemente, J. C., González, A., Fontana, L., et al. (2011). Diet drives convergence in gut microbiome functions across mammalian phylogeny and within humans. Science 332, 970-974. doi: 10.1126/science.1198719

Nawrot, R., Barylski, J., Tomaszewski, E., Jerzak, L., GoŸdzicka-Józefiak, A., Jêdrzejewski, S., et al. (2009). Identification of bacterial species in white stork chicks in Poland using PCR method and sequencing of bacterial $16 \mathrm{~S}$ rRNA. Pol. J. Environ. Stud. 18, 301-304. Available online at: http://www.cabdirect.org/abstracts/20093110993.html;jsessionid= EDBEAC7C7143C15C66F1B8324CE80C0E

Nelson, T. M., Rogers, T. L., and Brown, M. V. (2013). The gut bacterial community of mammals from marine and terrestrial habitats. PLoS ONE 8:e83655. doi: 10.1371/journal.pone.0083655

Nelson, T. M., Rogers, T. L., Carlini, A. R., and Brown, M. V. (2012). Diet and phylogeny shape the gut microbiota of Antarctic seals: a comparison of wild and captive animals. Environ. Microbiol. 15, 1132-1145. doi: 10.1111/14622920.12022

Oakley, B. B., Lillehoj, H. S., Kogut, M. H., Kim, W. K., Maurer, J. J., Pedroso, A., et al. (2014). The chicken gastrointestinal microbiome. FEMS Microbiol. Lett. 360, 100-112. doi: 10.1111/1574-6968.12608

Oliver, W. R. B. (1955). New Zealand Birds. Wellington: A. H. \& A.W. Reed.

Pacheco, M. A., Alexandra García-Amado, M., Bosque, C., and Domínguez-Bello, M. G. (2004). Bacteria in the crop of the seed-eating green-rumped parrotlet. Condor 106, 139-143. doi: 10.1650/7406

Pérez-Cobas, A. E., Gosables, M. J., Friedrichs, A., Knecht, H., Artacho, A., Eismann, K., et al. (2013). Gut microbiota disturbance during antibiotic therapy: a multi-omic approach. Gut 62, 1591-1601. doi: 10.1136/gutjnl-2012303184

Potti, J., Moreno, J., Yorio, P., Briones, V., García-Borboroglu, P., Villar, S., et al. (2002). Bacteria divert resources from growth for magellanic penguin chicks. Ecol. Lett. 5, 709-714. doi: 10.1046/j.1461-0248.2002.00375.x

Powers, D. R., Van Hook, J. A., Sandlin, E. A., and McWhorter, T. J. (2010). Arthropod foraging by a southeastern Arizona hummingbird guild. Wilson J. Ornithol. 122, 494-502. doi: 10.1676/09-179.1

Preest, M. R., Folk, D. G., and Beuchat, C. A. (2003). Decomposition of nitrogenous compounds by intestinal bacteria in hummingbirds. Auk 120, 1091-1101. doi: 10.1642/0004-8038(2003)120[1091:DONCBI]2.0.CO;2

Pritchard, P. J. (1972). Digestion of sugars in the crop. Comp. Biochem. Physiol. A Mol. Integr. Physiol. 43, 195-205. doi: 10.1016/0300-9629(72)90482-3

Roggenbuck, M., Schnell, I. B., Blom, N., Bælum, J., Bertelsen, M. F., Pontén, T. S., et al. (2014). The microbiome of New World vultures. Nat. Commun. 5, 5498. doi: 10.1038/ncomms6498

Rubio, L. A., Brenes, A., Setién, I., de la Asunción, G., Durán, N., and Cutuli, M. T. (1998). Lactobacilli counts in crop, ileum and caecum of growing broiler chickens fed on practical diets containing whole or dehulled sweet lupin (Lupinus angustifolius) seed meal. British Poult. Sci. 39, 354-359.

Ruiz-Rodríguez, M., Soler, J. J., Lucas, F. S., Heeb, P., Palacios, M. J., MartínGálvez, M., et al. (2009). Bacterial diversity at the cloaca relates to an immune response in magpie Pica pica and to body condition of great spotted cuckoo Clamator glandarius nestlings. J. Avian Biol. 40, 42-48. doi: 10.1111/j.1600048X.2008.04471.X

Ryu, H., Grond, K., Verheijen, B., Elk, M., Buehler, D. M., and Santo Domingo, J. W. (2014). Intestinal microbiota and species diversity of Campylobacter and Helicobacter spp. in migrating shorebirds in Delaware Bay. Appl. Environ. Microbiol. 80, 1838-1847. doi: 10.1128/AEM.03793-13

Ryu, H., Lu, J., Vogel, J., Elk, M., Chávez-Ramírez, F., Ashbolt, N., et al. (2012). Development and evaluation of a quantitative PCR assay targeting sandhill crane (Grus canadensis) fecal pollution. Appl. Environ. Microbiol. 78, 4338-4345. doi: 10.1128/AEM.07923-11

Santos, S. S., Pardal, S., Proença, D. N., Lopes, R. J., Ramos, J. A., Mendes, L., et al. (2012). Diversity of cloacal microbial community in migratory shorebirds that use the Tagus estuary as stopover habitat and their potential to harbor and disperse pathogenic microorganisms. FEMS Microbiol. Ecol. 82, 63-74. doi: 10.1111/j.1574-6941.2012.01407.x

Scupham, A. J. (2007). Succession in the intestinal microbiota of preadolescent turkeys. FEMS Microbiol. Ecol. 60, 136-147. doi: 10.1111/j.1574-6941.2006.00245.x

Scupham, A. J., Patton, T. G., Bent, E., and Bayles, D. O. (2008). Comparison of the cecal microbiota of domestic and wild turkeys. Microb. Ecol. 56, 322-331. doi: $10.1007 /$ s00248-007-9349-4 
Shabbir, M. Z., Park, J., Muhammad, K., Rabbani, M., Rana, M. Y., and Harvill, E. T. (2014). Culture independent analysis of respiratory microbiome of houbara bustard (Chlamydotis undulata) revealed organisms of public health significance. Int. J. Agric. Biol. 16, 222-226. Available online at: http://www.fspublishers.org/published_papers/38558_..pdf

Shawkey, M. D., Pillai, S. R., Hill, G. E., Siefferman, L. M., and Roberts, S. R. (2007). Bacteria as an agent for change in structural plumage color: correlational and experimental evidence. Am. Nat. 169, S112-S121. doi: 10.1086/5 10100

Singh, P., Karmi, A., Devendra, K., Waldroup, P. W., Cho, K. K., and Kwon, Y. M. (2013). Influence of penicillin on microbial diversity of the cecal microbiota in broiler chickens. Poult. Sci. 92, 272-276. doi: 10.3382/ps.2012-02603

Spor, A., Koren, O., and Ley, R. (2011). Unravelling the effects of the environment and host genotype on the gut microbiome. Nat. Rev. Microbiol. 9, 279-290. doi: $10.1038 /$ nrmicro2540

Stanley, D., Denman, S. E., Hughes, R. J., Geier, M. S., Crowley, T. M., Chen, H., et al. (2012). Intestinal microbiota associated with differential feed conversion efficiency in chickens. Appl. Microbiol. Biotechnol. 96, 1361-1369. doi: 10.1007/s00253-011-3847-5

Stanley, D., Geier, M. S., Hughes, R. J., Denman, S. E., and Moore, R. J. (2013). Highly variable microbiota development in the chicken gastrointestinal tract. PLoS ONE 8:e84290. doi: 10.1371/journal.pone.0084290

Stevens, C. E., and Hume, I. D. (1998). Contributions of microbes in vertebrate gastrointestinal tract to production and conservation of nutrients. Physiol. Rev. 78, 393-427.

Su, H., McKelvey, J., Rollins, D., Zhang, M., Brightsmith, D. J., Derr, J., et al. (2014). Cultivable bacterial microbiota of Northern Bobwhite (Colinus virginianus): a new reservoir of antimicrobial resistance? PLoS ONE 9:e99826. doi: 10.1371/journal.pone.0099826

Suarez, R. K. (1992). Hummingbird flight: sustaining the highest massspecific metabolic rates among vertebrates. Experientia 48, 565-570. doi: 10.1007/BF01920240

Sullam, K. E., Essinger, S. D., Lozupone, C. A., O'connor, M. P., Rosen, G. L., Knight, R., et al. (2012). Environmental and ecological factors that shape the gut bacterial communities of fish: a meta-analysis. Mol. Ecol. 21, 3363-3378. doi: 10.1111/j.1365-294X.2012.05552.x

Sulzner, K., Kelly, T., Smith, W., and Johnson, C. K. (2014). Enteric pathogens and antimicrobial resistance in turkey vultures (Cathartes aura) feeding at the wildlife-livestock interface. J. Zoo Wildl. Med. 45, 931-934. doi: 10.1638/20120217.1

Swanson, K. S., Dowd, S. E., Suchodolski, J. S., Middelbos, I. S., Vester, B. M., Barry, K. A., et al. (2011). Phylogenetic and gene-centric metagenomics of the canine intestinal microbiome reveals similarities with humans and mice. ISME J. 5, 639-349. doi: 10.1038/ismej.2010.162

Tausova, D., Dolejska, M., Cizek, A., Hanusova, L., Hrusakova, J., Svoboda, O., et al. (2012). Escherichia coli with extended-spectrum $\beta$-lactamase and plasmid-mediated quinolone resistance genes in great cormorants and mallards in Central Europe. J. Antimicrob. Chemother. 67, 1103-1107. doi: $10.1093 / \mathrm{jac} / \mathrm{dks} 017$

Torok, V. A., Hughes, R. J., Mikkelsen, L. L., Perez-Maldonado, R., Balding, K., Macalpine, R., et al. (2011). Identification and characterization of potential performance-related gut microbiotas in broiler chickens across various feeding trials. Appl. Environ. Microbiol. 77, 5868-5878. doi: 10.1128/AEM. 00165-11

Torok, V. A., Ophel-Keller, K., Loo, M., and Hughes, R. J. (2008). Application of methods for identifying broiler chicken gut bacterial species linked with increased energy metabolism. Appl. Environ. Microbiol. 74, 783-791. doi: 10.1128/AEM.01384-07

Tsai, H.-J., and Huang, C.-W. (2006). Phenotypic and molecular characterization of isolates of Ornithobacterium rhinotracheale from chickens and pigeons in Taiwan. Avian Dis. 50, 502-507. doi: 10.1637/7527-031906R.1

Turnbaugh, P. J., Ley, R. E., Hamady, M., Fraiser-Ligget, C. M., Knight, R., and Gordon, J. I. (2007). The human microbiome project. Nature 449, 804-810. doi: 10.1038 /nature 06244

Tyson, G. W., Chapman, J., Hugenholtz, P., Allen, E. E., Ram, R. J., Richardson, P. M., et al. (2004). Community structure and metabolism through reconstruction of microbial genomes from the environment. Nature 428, 37-43. doi: 10.1038 /nature 02340
Tyson, G. W., Lo, I., Baker, B. J., Allen, E. E., Hugenholtz, P., and Banfield, J. F. (2005). Genome-directed isolation of the key nitrogen fixer Leptospirillum ferrodiazotrophum sp. nov. from an acidophilic microbial community. Appl. Environ. Microbiol. 71, 6319-6324. doi: 10.1128/AEM.71.10.6319-63 24.2005

Unno, T., Jang, J., Han, D., Kim, J. H., Sadowsky, M. J., Kim, O. S., et al. (2010). Use of barcoded pyrosequencing and shared OTUs to determine sources of fecal bacteria in watersheds. Environ. Sci. Technol. 44, 7777-7782. doi: $10.1021 / \mathrm{es} 101500 \mathrm{z}$

Van Der Wielen, P. W., Biesterveld, S., Notermans, S., Hofstra, H., Urlings, B. A., and Van Knapen, F. (2000). Role of volatile fatty acids in development of the cecal microflora in broiler chickens during growth. Appl. Environ. Microbiol. 66, 2536-2540. doi: 10.1128/AEM.66.6.2536-2540.2000

Van Der Wielen, P. W. J. J., Keuzenkamp, D. A., Lipman, L. J. A., van Knapen, F., and Biesterveld, S. (2002). Spatial and temporal variation of the intestinal bacterial community in commercially raised broiler chickens during growth. Microb. Ecol. 44, 286-293. doi: 10.1007/s00248-002-2015-y

Van Dongen, W. F. D., White, J., Brandl, H. B., Moodley, Y., Merkling, T., Leclaire, S., et al. (2013). Age-related differences in the cloacal microbiota of a wild bird species. BMC Ecol. 13:11. doi: 10.1186/1472-6785-13-11

Vela, A. I., Casas-Díaz, E., Fernández-Garayzábal, J. F., Serrano, E., Agustí, S., Porrero, M. C., et al. (2014). Estimation of cultivable bacterial diversity in the cloacae and pharynx in Eurasian Griffon vultures (Gyps fulvus). Microb. Ecol. 3, 597-607. doi: 10.1007/s00248-014-0513-3

Waite, D. W., Deines, P., and Taylor, M. W. (2012). Gut microbiome of the critically endangered New Zealand parrot, the kakapo (Strigops habroptilus). PLoS ONE 7:e35803. doi: 10.1371/journal.pone.00 35803

Waite, D. W., Deines, P., and Taylor, M. W. (2013). Quantifying the impact of storage procedures for faecal bacteriotherapy in the critically endangered New Zealand parrot, the kakapo (Strigops habroptilus). Zoo Biol. 32, 620-625. doi: 10.1002/zoo.21098

Waite, D. W., Dsouza, M., Biswas, K., Ward, D. F., Deines, P., and Taylor, M. W. (2015). Microbial community structure in the gut of the New Zealand insect Auckland tree weta (Hemideina thoracica). Arch. Microbiol. 4, 603-612. doi: 10.1007/s00203-015-1094-3

Waite, D. W., Eason, D. K., and Taylor, M. W. (2014). Influence of handrearing and bird age on the faecal microbiota of the critically endangered kakapo. Appl. Environ. Microbiol. 80, 4650-4658. doi: 10.1128/AEM.00 975-14

Waite, D. W., and Taylor, M. W. (2014). Characterising the avian gut microbiota: membership, driving influences and potential function. Front. Microbiol. 5:223. doi: $10.3389 /$ fmicb. 2014.00223

Watkins, B. A., and Miller, B. F. (1983). Competitive gut exclusion of avian pathogens by Lactobacillus acidophilus in gnotobiotic chicks. Poult. Sci. 9, 1772-1779. doi: 10.3382/ps.0621772

Wei, S., Morrison, M., and Yu, Z. (2013). Bacterial census of poultry intestinal microbiome. Poult. Sci. 92, 671-683. doi: 10.3382/ps.2012-02822

Wienemann, T., Schmitt-Wagner, D., Meuser, K., Segelbacher, G., Schink, B., Brune, A., et al. (2011). The bacterial microbiota in the ceca of Capercaillie (Tetrao urogallus) differs between wild and captive birds. Syst. Appl. Microbiol. 34, 542-551. doi: 10.1016/j.syapm.2011.06.003

Wright, A. G., Northwood, K. S., and Obispo, N. E. (2009). Rumen-like methanogens identified from the crop of the folivorous South American bird, the hoatzin (Opisthocomus hoazin). ISME J. 3, 1120-1126. doi: 10.1038/ismej.2009.41

Xenoulis, P. G., Gray, P. L., Brightsmith, D., Palculict, B., Hoppes, S., Steiner, J. M., et al. (2010). Molecular characterization of the cloacal microbiota of wild and captive parrots. Vet. Microbiol. 146, 320-325. doi: 10.1016/j.vetmic.2010. 05.024

Xu, J., Bjursell, M. K., Himrod, J., Deng, S., Carmichael, L. K., Chiang, H., et al. (2003). A genomic view of the human-Bacteroides thetaiotaomicron symbiosis. Science 299, 2074-2076. doi: 10.1126/science.1080029

Yanega, G. M., and Rhubega, M. A. (2004). Hummingbird jaw bends to aid insect capture. Nat. Commun. 428, 615. doi: 10.1038/428615a

Yatsunenko, T., Rey, F. E., Manary, M. J., Trehan, I., Dominguez-Bello, M. G., Contreras, M., et al. (2012). Human gut microbiome viewed across age and geography. Nature 486, 222-227. doi: 10.1038/nature11053 
Yeoman, C. J., Chia, N., Jeraldo, P., Sipos, M., Goldenfeld, N. D., and White, B. A. (2012). The microbiome of the chicken gastrointestinal tract. Anim. Health Res. Rev. 13, 89-99. doi: 10.1017/S1466252312000138

Zaneveld, J. R., Lozupone, C., Gordon, J. I., and Knight, R. (2010). Ribosomal RNA diversity predicts genome diversity in gut bacteria and their relatives. Nucleic Acids Res. 38, 3869-3879. doi: 10.1093/nar/gkq066

Zhang, B., Yang, X., Guo, Y., and Long, F. (2011). Effects of dietary lipids and Clostridium butyricum on the performance and the digestive tract of broiler chickens. Arch. Anim. Nutr. 65, 329-339. doi: 10.1080/1745039X.2011. 568274

Zhang, L., Cao, G. T., Zeng, X. F., Zhou, L., Ferket, P. R., Xiao, Y. P., et al. (2014). Effects of Clostridium butyricum on growth performance, immune function, and cecal microflora in broiler chickens challenged with Escherichia coli K88. Poult. Sci. 93, 46-53. doi: 10.3382/ps.2013-03412
Zhu, X. Y., Zhong, T., Pandya, Y., and Joerger, R. D. (2002). 16S rRNA-based analysis of microbiota from the cecum of broiler chickens. Appl. Environ. Microbiol. 68, 124-137. doi: 10.1128/AEM.68.1.124-137.2002

Conflict of Interest Statement: The authors declare that the research was conducted in the absence of any commercial or financial relationships that could be construed as a potential conflict of interest.

Copyright (c) 2015 Waite and Taylor. This is an open-access article distributed under the terms of the Creative Commons Attribution License (CC BY). The use, distribution or reproduction in other forums is permitted, provided the original author(s) or licensor are credited and that the original publication in this journal is cited, in accordance with accepted academic practice. No use, distribution or reproduction is permitted which does not comply with these terms. 